\title{
Ayurveda and remedial plants in medication
}

\author{
Vinay Sharma \\ Amity Institute of Biotechnology, Amity University Rajasthan, Jaipur-303007, Rajasthan, India
} Article Info

Article history : Received 25 April 2021, Revised 12 June 2021, Accepted 13 June 2021 Published online 30 June 2021

\section{Introduction}

Although, a huge number of exact pharmaceutical products, mostly synthetic, are available, yet the plants still have an indispensible status in contemporary therapeutical systems because of multiple reasons, viz., safety, free of side effects and peoples' faith in Ayurveda.

\section{Ayurveda}

Ayurveda, decodedas 'the science of life', is an Indian method of medicine, based on concrete basics that are effusively unrelenting by long investigations and ethical propositions, way back to approximately 1,000 BCE. In India, Siddha, Ayurveda and Unani systems are the recognized and most systematized amongst the customary systems of medicine.

Ayurveda includes all aspects of life and disease, viz., physiology, pathology, anatomy, symptomatology and medical preparations to get rid of a disease. Acquaintance of Ayurvedic system has regrettably been confined to India and the western world is mostly unaware of it. Even in urbanized India, this old-style medication has not been able to get its due reputation. There are several reasons for this ignorance, for instance, one of the key causes for this is that the early texts on Ayurveda were written in Sanskrit language which was used in awfully in significant groups of the huge populace of India. Still, a significant substance of Ayurvedic acquaintance is in the form of antique palm leaf manuscripts concealed in inaccessible archives and secluded collections, hence limited to a few individuals. Consequently, Ayurveda has been missing from focus and does not appreciate the significance and acceptance it rates. A sporadic attempt by a few Indians, on its relic, vastness and status, has been hugely insufficient for Ayurveda.

Ayurveda is an extremely coherent system of medicine and abstractly contradictory from the traditional or home-based medicine, which is largely on the historical experience of discrete medicinal practice, and from Jadi-booti which is profoundly laden with occult observations.

The Ayurvedic system propagated dynamically till about 1300 $\mathrm{CE}$, however, during its commencement, it registered the end of a magnificent era of development and regularization. In the medieval times, by inquisitive amalgamation of situations, the rasayana practices returned, and the medications and preparations developed in this system, got assimilated into Ayurveda. Ayurveda had a wonderful past during the Buddhist eras. It was educated in
Universities such as Taxsila and Nalanda. Succeeding ethnic uprisings, mystical resurgence and some political interference have triggered its deterioration. Jainism campaigns of complete pacifism have also exaggerated applications of Charaka Samhitha, as many animal-based products were used as remedy. Surgery was also completely excluded because of non-violence motive. Human body examinations were prohibited at that time (Rao, 2002).

Afterward, Muslim rulers conquered India causing a stern cultural change. Mughal concepts of medicine were encouraged over Ayurveda during that time. Ahead, the European settlement and introduction of their medicinal practices in India promoted the supremacy of allopathy which resulted in enormous impairment to the Ayurveda in the country.

After Indian independence, the condition took considerable time to improve as far as Ayurveda is concerned. Surprisingly, this very core Indian systems of medication attained governmental acknowledgment only after the adoption of National Health Policy in the year 1983. After that, the standing of Ayurvedic tutelage has upgraded leisurely, and even till date, this system of medication is not the preferred choice of medical aspirants. As a consequence, the Central Council of Indian Medicine started to administers this aspect. The matter is then motivated better after the creation of the Department of Indian Systems of Medicine and Homoeopathy, in the year 1995, by the Ministry of Health and Family Welfare. The State Governments were also involved and as a result, many colleges started to teach Ayurveda at the degree and postgraduate levels. With the purpose of scientific validation and exploration of the veiled possessions of various AYUSH systems of medicine, Govt. of India has established different research institutions, research councils, etc. (Khan, 2020). Recently, Central Council for Research in Ayurveda and Siddha (CCRAS), New Delhi has taken great initiatives.

\section{The magnitudes of ayurveda}

Though, the aims of Ayurveda are to keep all the humans healthy and fit with calm mind, yet the treatment of diseased person has not been the lone aim of Ayurveda. It is apprehensive with coordinating worldly behavior and divinequest through the understanding of the factual relationships amid the intricate body, cognizance and soul and the ever lasting world. The eventual culmination is not just routine pleasure but divineraise. To attain its purposes, Ayurveda established into an inclusive compendium of acquaintance in curative subjects like gynecology, obstetrics, 
genetics, etiology, analysis, therapeutics, surgical operations, physiology, biology, ethics, dietetics, personal cleanliness, precautionary treatment and community medication.

The Ayurvedic texts, Samhithas (literature) are illustrious by cautious and strong interpretations, comprehensive and categorized information, and acompetent exhibition of the accessible acquaintance in medicine and associated subjects that are supplemented to medicine.

\section{The foundation literature of ayurveda}

The expositions called Samhithas written by Charaka, Sushrutha and Ashtangahridaya, are the chief foundation literature of Ayurveda. Charaka Samhitha deals primarily with physiology, anatomy, pathology, etiology, and prognosis. It contains 150 chapters under eight sections. Sushruta Samhitha shows essentially the similar outline, but considered surgery with great significance and integrity. In fact, ideology of Sushrutha believed surgery as the most ancient and most effective of the eight branches of curative acquaintance. Sushruta Samhitha holds six sections and 184 chapters. He described approximately 300 diverse operations engaging 42 dissimilar surgical procedures and 121 diverse types of instruments (Rao, 2002). Excitingly, even plastic surgery including skin grafting was seemingly a common exercise in that period.

\section{The branches of ayurveda}

Eight specialized branches of Ayurveda, known as chikisas are of common practice, viz., i. Kaaya, ii. Baala, iii. Graha, iv. Shalakya, v. Shalya, vi. Visha, vii. Jara, viii. Vaajikara Chikitsas.

Ayurveda is extremely settled in detailed notional foundations, which are based on interpretations and metaphysical perceptive. An elementary accepting of these facets is an indispensable requirement to the considerate of the working of this system (Rao, 2002).

\section{The panchamahabhoothas}

The early Indians assumed that both the Universe and the organisms are formed by the following five basic elements (the panchamahabhoothas) : a. Prithvi, b. Jala, c. Tejas, d. Vaayu, and e. Aakasha.

\section{The humoural theory of ayurveda (Tridosha)}

Concept of humoural pathology is one of the earliest concepts of medicine described in Ayurveda, Unani, Siddha, Tibetan and Chinese medical systems. This humoral theory is naall-inclusive tactic to the three main branches of medicine, pathology, physiology and treatment. An appropriate valuation of the Ayurveda as a science is principally reliant on the thoughtfulness of the united 'thridosha concept', the implication and real form of these three humours, viz., Vaata (Air and Fire), Pitta (Light), and Kapha (Earth and Water). These three doshas are again sectioned, into five types by some theoreticians of Ayurveda.While the Siddha and the Tibetan systems have also humoural concepts like that of Ayurveda, but the Unani system identifies four humours and the Chinese system dependent on only two.

For the treatment of the thridoshas the diagnosis of specific symptoms affecting the bodily elements in their respective spheres of influences is necessary. The characteristic etiology and prediction of diverse diseases are due to the huge amount of possible variations and combinations of the three humours. Rationally, healthcare depends primarily in the detection of the unbalancedhumours and evaluating the harshness of imbalance, and secondarily in recognizing the exact sickness by incident history and indications. Equipped with this information and that of the diverse plant based drugs, the Ayurvedic practitioner attempts to correct the specific disproportion and augmentations and eventually an effective cure is obtainable (Khare, 2007).

\section{Use of plants in folk medicine}

The enormous advances made by investigative biochemistry, electronics and other branches of science have greatly backed the development of the biomedicine that has attained wonders in medicines. But, it resulted into extra ordinary shoot up in costs of these advance medicines and putting it away from the grasp of the most of the world's populace. Allopathic medicines usually serve only sectional inhabitants of the total populace in the evolving nations (Naranjo, 1981, 1995). The remaining populace manages its health only through the old-fashioned medicinal system, which is fundamentally based on the use of straight forwardly available either free or low-cost healing plants. The use of remedial plants is desirable for them because of following aspects: (i) their low cost; (ii) habitually they are the only option obtainable; (iii) research based validation regarding the occurrence of therapeutically vigorous phytoconstituents; (iv) they have relatively very few detrimental side effects and, hence can be taken directly as folk medicine, unlike the synthetic drugs.

\section{Uprising of Ayurveda}

There is transformed curiosity in using plants in treatment of various diseases due to the discovery of antimalarial drug artemisin in the species of Cinchona. This healing attainment of chloroquine and its man-made products in the cure of malaria had revolutionized the field of phytomedicines. Consequently, the rush in demand for these plant-based products to treat malaria became outside the manufacturing capability of the herbal extraction laboratories worldwide (Naranjo, 1995). Similar situation is with another deadly disease, tuberculosis, where the previous successful synthetic drug based therapy now becoming futile against the pathogen's acquired resistance. Therefore, an imperative need is to find operative drugs to counter this disease.

As evident, the synthetic chemistry up till now had only a slight attainment in procurement of effective drugs in the cure of several viral diseases. Although, immunotherapy has attained profuse accomplishment, still the vaccines for all viral diseases are missing (Naranjo, 1995). Considering this, it is imaginable that plants would be valuable to cure viral diseases, as numerous plant species like neem showed excellent antimicrobial and antiviral potential, so there is a huge possibility regarding plant diversity to be worked in this direction.

Contemporary medicine depends on numerous plant species that are also used in customary medicine, although they need great improvement regarding characterization and extraction. For instance, digioxin extracted from Digitalis purpurea and Digitalis lanata could not be produced, and synthetic form of vincristine (Cathranthus roseus) has been established to be inadequately effective than the natural product (Pearce and Moran, 1994). Albeit, biotechnological 
trials, comprising micro-organisms to synthesize or transform healing compounds are engaged, they function merely on the base of a natural product (Principe, 1989). Therefore, for validation of plant based folk medicines, a lot of work has to be done to authorize their healing influence.

Some plants are valuable as supplementsto other methods of treatment. These plant species can benefit in the cure of many diseases, the several Ayurvedic preparations encompassing numerous plants species are examples of supplement, where invariably individual species or two (or few) species are the key constituents.

Plants are worth while in the cure of many common and frequent minor sicknesses, e.g., the common cold and cough, slight stomach ache, diarrhea, etc. Decoctions of many plant species, like ginger, garlic, cumin, pepper, etc., are well recognized in folk medicine all over the world, to offerre spite from these sicknesses. These preparations can also contribute in the improvement of general immunity of the individuals.

However, the great plant wealth is still available to work with regarding the extraction of important bioactive compounds and their commercialization. It became evident, after numerous futile efforts, that only minor figures of natural products are pliable for artificial production. It is also apparent that the potentials of scheming and in sincerely producing new assemblies for healing purposes are inadequate. This led to the comprehension that remedially active phytochemical structures should be set up among the constituents of plants and these should create the basis for evolving novel structures or for augmenting them, through well thought structural adjustments.

Some phytoproducts agonize from certain drawbacks, for example, their existence in miniscule quantities in the source plant, meager solubility, shortconstancy, deprived absorption, improperdispersal, failure to grasp the aim, etc. A structural modification called 'prodrug' is efficiently used to improve the competence of these plantbased drugs. For instance, aspirin is a 'prodrug' of salicylic acid (Wermuth, 1981). Vindesine is a 'prodrug' of alkaloids obtained from Catharanthus roseus (Cassady et al., 1981). A good example of this approach is vincristine (antileukaemia drug) which is in excessive demand, hurts from the shortcoming of very squat yields from the source plant, and so is excessively costly (Wall and Wani, 1981). Vinblastine, one more anticancer drug from the Catharanthus roseus exists at levels of 1,000 times higher than vincristine, and relatively cost effective than vincristine. Vinblastine is nowadays being used as the 'parent drug' to get, through structural modifications, the 'prodrug', vincristine.

Therefore, several methods of refining the performance of native drugs are now available which are cost and time effective. These with the assistance of several computers programmes in structure resolves have made the procedure easier than the past.

Recognizing these merits of the extensive usage of medicinal plants and of further unified explorations related to validation and characterization of phytoconstituents can guideand encourage the scientific community working in the field of traditional medicines to obtain all the possible benefits for the large portion of deprived population of the world. Since, nature has created everything in this universe with the purpose, therefore, it is our duty to do the ecofriendly exploration of the floral wealth to get rid of many ailments of our lives. In order to reach its objective, it is suggested that governments integrate the advantageous facets of customary medicine, particularly the usage of medicinal plants, in their primary healthcare procedures.

However, for generating awareness about the phytochemical based formulations in scientific community and elsewhere the requirement of quality publication is indispensable. In this direction, the scientific journals play vital roles by releasing well analyzed and appraised quality research articles frequently. In contemporary scenario, it is not an easy task to perform as the accomplishment of any journal relies on getting worthy research outcomes including scientific perceptions in the form of well composed articles that are rigorously reviewed by the experts of that field who act as reviewers. The journals should assist the budding authors to publish their articles that must be indexed/listed in reputed database.

The field of Phytomedicine is actually a multifaceted arena including botany, biochemistry, pharmacology, ethnobotany, molecular biology, biostatistics, etc. Considering this, amid thousands of journals, researchers always search a platform where they can think to publish their findings after their innovative and strenuous hard work. Phytomedicines related research need a dedicated platform where a team of experts is available to help them in lucid publication with critical analysis of their findings. In this perspective, 'Annals of Phytomedicine: An International Journal' with both online and high quality, glossy print versions, is an excellent channel to publish quality research outcomes in the area of medicinal plants. This journal has an excellent team of committed scientists and academicians who are serving altruistically to provide timely publication of progressive and contemporary research in this area. It is highly difficult task to perform but this journal is doing so highly successfully since many years. I am delighted to appreciate that the journal, 'Annals of Phytomedicine: An International Journal' is holding its flag high and gaining well deserved popularity and is highly acclaimed by the peers.

\section{Conflict of interest}

The author declares that there are no conflicts of interest relevant to this article.

\section{References}

Cassady, J.M.; Chang, C.J. and McLaughlin, J.E. (1981). Recent advances in the isolation and structural elucidation of antineoplastic agents in higher plants. In: Natural products as medicinal agents. (eds.) Beal, J.L. and Reinhard, E. Suppl. Planta Medica. Hippokrates Verlag, Stuttgart. pp:93-124.

Compadre, C.M.; Pezzuto, J.M.; Kinghorn, A.D. and Kalmath, S.K. (1985). Hernandulcin: An intensely sweet compound discovered by review of ancient literature. Science, 227:417-419.

Khan, A.A. (2020). Role of Unani medicine in empowering national healthcare. Ann. Phytomed., 9(2):1-5. http://dx.doi.org/ 10.21276/ap.2020.9.2.1.

Khare, C.P. (2007). Indian medicinal plants: An illustrated dictionary. Springer-Verlag Berlin/Heidelberg.

Naranjo, P. (1970). Plant aspsicotomimeticas y bioquimicas de la mente. Terapia, 25:87. 
Naranjo, P. (1981). Farmacologia y medicina traditional. In Fundamentos de Farmacologia Medica. (eds.) Samaniego, E. and Escaleras, R. Universitat Central, Quito.

Naranjo, P. (1995). The urgent need for the study of medicinal plants. In Ethnobotany: Evolution of a discipline. (eds.) Schultes, R.E. and Reis, S. von., Chapman and Hall, London, pp:362-368.

Principe, P. (1989). The economic significance of plants and their constituents as drugs. In Economic and medicinal plant research. (eds.) Wagner, H., Hikino, H. and Farnsworth, N. ol. 3. Academic Press, London, pp:1-17.
Rao, C.K. (2002). Database of Medicinal Plants. Govt. of Karnataka.

Wall, M.E. and Wani, M.C. (1981). Structure activity relationship of plant antitumour agents related to camptothecin and the quassinoids. In Natural products as medicinal agents. (eds.) Beal, J.L. and Reinhard, E. Suppl. Plants Medica. Hippokrates Verlag, Stuttgart., pp:125-149.

Wermuth, C.G. (1981). Modulation of natural products in order to improve their pharmacokinetic properties. In Natural products as medicinal agents. (eds.) Beal, J.L. and Reinhard, E. Suppl. Planta Medica. Hippokrates Verlag, Stuttgart., pp:185-215. 


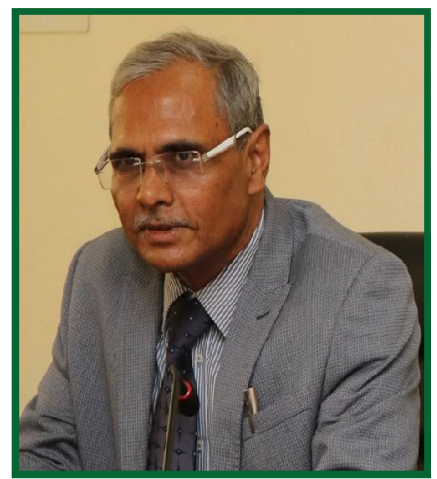

Professor Vinay Sharma

Dean Research and Director, Amity Institute of Biotechnology, Amity University Rajasthan,

Jaipur-303002, Rajasthan, India

\section{Biography}

Professor Vinay Sharma, is currently serving as Dean Research and Director, Amity Institute of Biotechnology, Amity University, Rajasthan, Jaipur since May 2018 and has over 36 years university level experience of teaching and research in Plant Sciences/ Biotechnlology. Earlier he has served as Associate Professor at Department of Biotechnology at University of Roorkee (I.I.T Roorkee) during 1986-96 and later as Professor and Head, Department of Bioscience and Biotechnology and Dean, Faculty of Science and Technology at Banasthali Vidyapith during 1996-2018.

He has been honoured with many prestigious fellowships and awards in India and abroad. To mention a few: Prof. Sharma is a Fellow of National Academy of Sciences (FNASc), Fellow of Biotech Research Society (FBRS) and Fellow, The Indian Society of Genetics, Biotechnology Research and Development. He was honoured with Distinguished Scientist Award (2013) and later H.S. Srivastava Memorial Award-2016 by Society for Plant Research. He is a Mentor, DST-INSPIRE Programme. Earlier, he was awarded Zahoor Qasim Gold Medal by Society of Biosciences, Young Scientist Award by Indian Science Congress Association and has been a Member of the New York Academy of Sciences.

Professor Sharma had extensive international research experience as Visiting Scientist/ Professor at many institutions, viz., Institute of Botany, University of Koeln, Max Planck Institute, Koeln, Technical University, Darmstadt, Germany, University of Central Florida, USA and others. He was nominated to visit Germany and later to Hungary under the prestigious INSA bilateral exchange programme (INSADFG and INSA-HAS) and has been a DAAD fellow too.

His Broad Research Area is Plant Stress Biology/ Molecular Plant Physiology/ Biotechnology/ Bioinformatics. He has published 360 Full Research Papers with an h index of 33 and i10 Index of 98 with over 4000 citations. He has authored 8 books and is on the editorial board of several research journals. He has mentored 75 doctoral students in his supervision who are well placed and many of them are employed as faculty in Indian and Foreign Universities and Industries.

Professor Sharma has handled many university/department level major projects as well as R \& D Projects. For instance, he has been Coordinator, M.Sc. Biotechnology Programme, DBT, Coordinator, Centre for Bioinformatics, DBT and Coordinator, DST FIST Programme. Prof. Sharma has successfully handled research projects funded by different scientific agencies including DST, DBT, ICAR, UGC, DRDO, India, JSPS, Japan and DAAD, Germany as PI/Co-PI.

Professor Sharma has Chaired sessions and has delivered over 100 invited/ inaugural/ lead lectures in various symposia/ conferences in India and abroad including Spain, Portugal, U.K., Italy, China, Japan, USA, Hungary and Germany. He holds the life membership of 9 prestigious scientific bodies. Prof. Sharma has organized 2 International conference, 1 International symposium, 2 National Symposia and 12 National Workshops as Convener/ Co-convener/ Organizing Secretary. Besides have been Member of the Advisory Committee of at least 20 other confs/ symposia, etc.

In addition to his impeccable research and teaching credentials, Prof. Sharma has highly rich administrative experience, viz., 27 years as the Department Chair (Bioscience and Biotechnology) and 23 years as the Dean in various capacities. At Banasthali Vidyapith, he took many new initiatives of major research and development grant, such as DBT Centre for Bioinformatics, DST FIST programme and successfully handled the DBT supported M.Sc. Biotechnology Programme for 22 years. During his tenure as the Dept. Chair, many new programmes such as M.Tech Biotechnology, M.Sc. Bioinformatics, M.Sc. Applied Microbiology and Biotechology, B.Tech Biotechnology, B.Sc. Biotechnology were also started. He has been a member/ Convener of various academic and administrative bodies. He has also been a Member, Rajasthan State Biotechnology Advisory Board, Govt. of Rajasthan (2004-09); Expert Member, R \& D Project Committee, DST Rajasthan, Resource Person, DST, New Delhi Brainstorming session, Udaipur (2018), Expert Member, Bioinformatics Committee, State DST, Jaipur. He has also been Expert Member of Selection Committees of many Universities, Selection Committees of MHRD, Govt. of India; Expert Member, Board of Studies of more than 10 Universities, Academic Council, and Member, Advisory/Other Committees at several institutions (e.g., Member, DBT Programme Advisory Committee at Indore; Member, DBT Programme Advisory Committee at Bhopal; DBT Institutional Biosafety Committee at Central University Rajasthan; and many others).

Overall, Professor Sharma combines the qualities of a great researcher, teacher, administrator, communicator, motivator and adviser. Currently, he is mentoring several young scientists for innovative research at Amity University, Rajasthan, India. 